\title{
Impact of glycated hemoglobin level on severity of coronary artery disease in non-diabetic patients
}

\begin{abstract}
Background: Glycated hemoglobin values reflect two to three months average endogenous exposure to glucose including postprandial spikes in blood glucose level and have low intra-individual variability particularly in non-diabetic patients. Elevated hemoglobin $\mathrm{A} 1 \mathrm{C}$ is regarded as an independent risk factor for CAD in patients with or without DM. The purpose of this study is to determine the correlation between the level of Glycated hemoglobin (HbA1c), and the severity of coronary artery disease in non-diabetic patients.

Study design and methods: The study included four hundred and eight patients referred to coronary angiography in two tertiary centers. All patients were subjected to complete medical history, physical examination and full labs including HbA1c. Transthoracic echocardiogram and coronary angiography were done and the Gensini score was calculated. Normally distributed continuous variables will be represented as mean $\pm \mathrm{SD}$, or as the percentage of the sample. Comparison between high and low risk groups was done using two-tailed unpaired student $t$ test for continuous variables and the Pearson's chi-square test for categorical variables

Results: two hundred and ninety two patients $(71.6 \%)$ high risk group and $28.4 \%$ were low risk group. High risk group had $\mathrm{HbA} 1 \mathrm{c}(\mathrm{HbA} 1 \mathrm{c} 5.7-6.4 \%) \mathrm{mg} \%$ with mean $\mathrm{HbA} 1 \mathrm{c}$ of $6.1 \pm 0.3$. The mean Gensini score was $39.9 \pm 34.9$. The level of HbAlc was positively correlated with Gensini score $(\mathrm{r}=0.243, \mathrm{P}<0.05$, ) and RWMSI $(\mathrm{r}=0.103, \mathrm{p}=0.038)$ and negatively correlated with $\operatorname{LVEF}(\mathrm{r}=-0.146, \mathrm{p}=0.003)$.
\end{abstract}

Keywords: non-diabetic patients, coronary artery disease, cardiovascular diseases, glycated hemoglobin

\author{
Volume 7 Issue 4 - 2016
}

\author{
Noureldin Sahal,' Azza Farrag,' Waleed \\ Ammar,' Ahmed hegab ${ }^{2}$ \\ 'Department of Cardiovascular Medicine, Kasr Alainy Hospital, \\ Cairo University, Egypt \\ ${ }^{2}$ National Heart Institute, Egypt
}

Correspondence: Noureldin Sahal, Department of Cardiovascular Medicine, Kasr Alainy Hospital, Cairo University, Egypt, Tel 20I I5674449, Email nursamhoom@hotmail.com

Received: May 15, 2015 | Published: December 19, 2016
Abbreviations: 2-H OGTT, 2 hours oral glucose tolerance test; ACC, american college of cardiology; ACR, albumin-to-creatinine ratio; ACS, acute coronary syndrome; ADA, american diabetes association; ADAG, A1C-derived average glucose; ALL, average length lesion; ARIC, atherosclerosis risk in communities; AUC, area under the curve; BMI, body mass index; $\mathrm{CABG}$, coronary artery bypass grafting; CAD, coronary artery disease; CGM, continuous glucose monitoring; $\mathrm{CI}$, confidence interval; $\mathrm{CKD}$, chronic kidney disease; CRP, C-reactive protein; CVD, cardiovascular disease; DBP, diastolic blood pressure; DCCT, the diabetes control and complications trial; DM, diabetes mellitus; eAG, estimated average glucose; echo echocardiography; EEM, external elastic membrane; EF, ejection fraction; EPIC, european prospective investigation of cancer; FBG, fasting plasma glucose; FBS, fasting blood glucose; FDR, first degree relative; FRS, framingham risk score; GFR, glomular filtration rate; $\mathrm{HbA1c}$, glycated haemoglobin; $\mathrm{HbF}$, fetal haemoglobin; $\mathrm{HbS}$, hemoglobin s; HDL, high-density lipoprotein; HOPE, heart outcomes prevention evaluation; HPFS, health professionals follow-up study; $\mathrm{HR}$, hazard ratios; Hs-CRP, high sensitivity c-reactive protein; HTN, hypertension; IDL, intermediate-density lipoprotein; IFG, impaired fasting glucose; IGT, impaired glucose tolerance; IMT, intima media thickness; IVUS, intravascular ultrasound; JNC, joint of national committee; LAD, Left Anterior Descending Artery; LCX: Left Circumflex Artery; LDL: Low-Density Lipoprotein; LV: left ventricle; LVEF, left ventricular ejection fraction; MDCT, multi-detector computed tomography; MI, myocardial infarction; MRI, magnetic resonance imaging; MVD, multivessel disease; N, number; NDR, national diabetes register; NEFAs, nonesterified fatty acids; NGSP, national glycohemoglobin standardization program; NHANES, national health and nutrition examination survey; NHS, nurses' health study; NSTEMI, non ST segment elevation myocardial infarction; NWAHS, the north west adelaide health study; OGTT, oral glucose tolerance test; OHAs, oral hypoglycemic agents; OR, odds ratio; P: P-value; PAI-1, plasminogen activator inhibitor; pCAP, premature coronary atherosclerotic patients; PCI, percutaneous coronary intervention; PTCA, percutaneous transluminal coronary angioplasty; PWV, pulse wave velocity; RCA, right coronary artery; $\mathrm{RR}$, remodeling ratio; RWMSI, regional wall motion score index; SBP, systolic blood pressure; SD, standard deviation; SDR, second degree relative; SI, system international; SPSS, statistical package for the social sciences; STEMI, ST segment elevation myocardial infarction; SYNTAX, synergy between PCI With TAXUS ${ }^{\mathrm{TM}}$ and cardiac surgery; TC, total cholesterol; TG, triglyceride; US, united state; VLDL, very-low-density lipoprotein; WC, waist circumference; WHO, world health organization; Whtr, waist height ratio

\section{Aim of the work}

The aim of this work was to assess the relationship between the level of $\mathrm{HbAlc}$ and the severity of CAD, assessed by the Gensini score, among non-diabetic patients referred to coronary angiography as indicated clinically.

\section{Introduction}

Among the known risk factors for cardiovascular disease, diabetes mellitus (DM) ranks as one of the most potent. The excess risk for cardiovascular disease is two to eight folds higher in patients with diabetes mellitus compared to non diabetic individuals of similar age, sex and ethnicity. ${ }^{1,2}$ It has also been recognized that high normal fasting blood glucose and increasing hemoglobin A1C levels in individuals without diabetes mellitus are risk factors for cardiovascular events and subclinical atherosclerosis. ${ }^{3,4}$ 
Glycated hemoglobin values reflect two to three months average endogenous exposure to glucose including postprandial spikes in blood glucose level and have low intra-individual variability particularly in non-diabetic patients. ${ }^{5,6}$ New clinical practice recommendation from the American Diabetes Association advocates the use of hemoglobin A1c in diagnosis of diabetes mellitus largely on the basis of the established association between Glycated hemoglobin and microvascular disease. ${ }^{7-9}$

Elevated hemoglobin A1C is regarded as an independent risk factor for Coronary artery disease (CAD) in patients with or without DM, whereas levels of hemoglobin A1c less than 7\% deemed appropriate for reducing risk of vascular complications. ${ }^{10}$ The level of hemoglobin A1c has been correlated with number of vessels significantly diseased at time of coronary angiography. ${ }^{11,12}$ Moreover, it has been found that the prevalence of elevated hemoglobin A1c levels in patients undergoing coronary artery bypass grafting is high. ${ }^{13}$ Thus; the level of hemoglobin A1c may be correlated with the severity of coronary artery disease innon diabetic individuals.

\section{Study design and population}

This is a prospective study that included four hundred and eight patients referred to coronary angiography in two tertiary centers (Cairo University Hospitals and National Heart Institute) within a period of three months from January 2013 to April 2013. Patients who were referred to elective coronary angiography as indicated clinically were included in the study. The patients were subjected to complete medical history taking with special emphasis on:

a. History of other risk factors for coronary artery disease including: Hypertension and received medications, smoking status and family history of CAD.

Physical examination was performed by the treating physician with special emphasis on:

a. Identifying patients with hypertension. The diagnosis of hypertension is based on the JNC Seventh Report on Detection, Evaluation and Treatment of High Blood Pressure. ${ }^{14}$

b. Identifying the presence of obesity by measuring waist circumference and body mass index. The diagnosis of obesity is based on the Clinical Guidelines on the Identification, Evaluation, and Treatment of Overweight and Obesity in Adults. ${ }^{15}$

Blood samples were taken at the time of admission for $\mathrm{HbAlc}$, serum Creatinine, FPG levels and lipid profile in addition to routine measurements. Samples for FPG and serum Creatinine were taken after eight hours fasting. HbA1c was measured by TECO-diagnosticUSA which is not affected by anemia or renal problems and results reported as percentage of total hemoglobin.

\section{Exclusion criteria}

i. Diabetic patients.

ii. Patient not known diabetic but FBS more than $126 \mathrm{mg} / \mathrm{dl}$.

iii. Patient with $\mathrm{HbA} 1 \mathrm{c}$ more than $6.5 \%$.

iv. Normal Coronary angiography.

A transthoracic echocardiogram study was done to every patient to identify the estimated ejection fraction, regional wall motion abnormalities, cardiac chambers dimensions and associated valvular lesions as per American Society of Echocardiography guidelines and recommendations. ${ }^{16}$ Regional wall motion score index (RWMSI) was calculated. The echocardiographic machines used were Philips iE33 xMATRIX and GE Vivid 7.

Coronary angiography was performed by the femoral or radial approach in all subjects by Judkins technique. Images were recorded in multiple projections for left and right coronary arteries on a digital system. The coronary angiograms were done and reviewed by 2 cardiologists who were blinded for the characteristics of the patients during the interpretation; the difference in assessment was solved by consensus. The severity of CAD was assessed by using the Gensini score. ${ }^{17}$ It is a scoring system which allocates a numerical value for the degree of stenosis in a coronary artery and a multiplication factor that depends on which coronary artery is involved and where the stenosis is located in the coronary artery.

This scoring system has been used in several studies to establish a correlation between the severity of CAD and other factors. It grades narrowing of the lumen of the coronary artery and scores it as:
a. 1 for $1-25 \%$ narrowing.
b. 2 for $26-50 \%$ narrowing.
c. 4 for $51-75 \%$ narrowing.
d. 8 for $76-90 \%$ narrowing.
e. 16 for $91-99 \%$ narrowing.
f. 32 for a completely occluded artery.

The score is then multiplied by a factor according to the importance of the coronary artery as follows:

a. Left main stem lesion is 5 .

b. Proximal LAD and proximal LCX is 2.5 .

c. Mid LAD lesion is 1.5 .

d. Distal LAD, mid and distal LCX and RCA lesions is 1. Any branch is 0.5 .

\section{Data collection}

Data were collected regarding number of variables concurrently with hospital admission by the treating physicians and filled in prepared sheets.

These variables were:

\section{Personal data}

Name, age and gender.

\section{Clinical data}

\section{Risk factors for CAD}

Hypertension: History including duration of illness and medications received if present. Patients who were recently discovered to be hypertensive on presentation were reported as being hypertensive. The diagnosis of hypertension was based on the JNC Seventh Report on Detection, Evaluation and Treatment of High Blood Pressure. ${ }^{14}$

Dyslipidemia: Based on the lipid profile of the patient.

Smoking status: The patients were classified into two groups: Current smoker (who currently smoker or quit before less than five years) and non- smoker (who never smoke or quit smoking more than five years).

Family history of CAD: The family history define as a myocardial infarction (MI) or death from CAD in a first degree relative (ie, parent or sibling) prior to age 50 (males) or 60 (females). ${ }^{18}$ 


\section{Clinical diagnosis and the reason for coronary angiography}

a. Unstable angina pectoris.

b. Non ST segment elevation MI.

c. ST segment elevation MI.

Obesity: Weight, height and waist circumference were measured (the waist circumference is measured at a level midway between the lowest rib and the iliac crest). ${ }^{19}$ Body mass index was calculated ( fatness is most commonly assessed by body mass index (BMI) which is calculated by dividing an individual's weight measured in kilogram's by their height in meters squared ). The patients were classified as obese or non-obese according to the Clinical Guidelines on the Identification, Evaluation, and Treatment of Overweight and Obesity in Adults. ${ }^{15}$

\section{Echocardiographic data}

The estimated left ventricular ejection fraction and RWMSI were reported.

\section{Laboratory data}

a. FPG.

b. $\mathrm{HbA1c}$.

c. Total Cholesterol Level (TC).

d. Triglycerides (TG).

e. LDL-C.

f. HDL-C

g. Serum Creatinine.

\section{Angiographic data}

Severity of CAD as assessed by Gensini score.

\section{Statistical analysis}

The study population was stratified into high risk group ( $\mathrm{HbAlc}$ $5.7-6.4 \%)(\mathrm{n}=292)$ and a low risk group (HbA1c $<5.7 \%)(\mathrm{n}=$ 116). Continuous variables are expressed as means $\pm \mathrm{SD}$, whereas categorical variables are presented as absolute values and percentages. Differences between the two groups regarding continuous variables were analyzed by the unpaired Student's $t$ test or non-parametric Mann-Whitney U test. Categorical variables were compared using Pearson Chi Square test of Fisher's Exact test, as appropriate. Pearson's correlation coefficients were used to evaluate the relationship between $\mathrm{HbAlc}$ and Gensini score.

Logistic regression analysis was used to determine which of cardiovascular risk factors were the significant variables associated with severe coronary atherosclerosis (Gensini $>30)$. The following variables were included into the model: age, gender, hypertension, BMI, WC, HbAlc, TC and HDL-C. The sensitivity and specificity of $\mathrm{HbAlc}$ values in predicting severe coronary atherosclerosis was determined by constructing Receiver Operating Characteristic (ROC) curves. The sensitivity / specificity cut-off points were reported as percentages with corresponding $95 \%$ confidence intervals. Two-tailed $\mathrm{p}$ value $<0.05$ was considered significant. All statistical analyses were done using SPSSS version 16.0 software for windows (SPSS Inc. Chicago, IL).

\section{Discussion}

HbAlc reflects the average blood glucose concentrationsover the preceding $2-3$ months. There are advantagesof $\mathrm{HbAlc}$ testing compared with plasma glucose. The measurementof $\mathrm{HbAlc}$ is well standardized, and the biologicvariability is less, and does not require fasting. Inaddition, it is relatively unaffected by acute changes in glucose levels. In this study we examined the correlation between Glycosylated hemoglobin level among non- diabetic patients referred to coronary angiography and the severity of CAD by means of Gensini score.

The studied group included 408 patients referred to coronary angiography as indicated clinically over a period of three months. We excluded normal coronary angiograms and diabetics individuals (fasting glucose $>126 \mathrm{mg} / \mathrm{dl}$, Hbalc $>6.5$ and history of diabetes). The study population was stratified into high risk group (HbA1c 5.7 $-6.4 \%)(n=292)$ and a low risk group (HbA1c $<5.7 \%)(n=116)$. High risk group represented $71.6 \%$ of the whole group. Both Groups had comparable age and gender distribution, obesity parameters and laboratory results except for the clinical presentations, FH, BMI, FPG, $\mathrm{HbAlc}$ and serum Creatinine. Also there is a significant difference between two groups regarding LVEF, RWMSI and Gensini score.

We demonstrated that the level of $\mathrm{HbA} 1 \mathrm{c}$ is positively correlated with the severity of CAD. The level of $\mathrm{HbA} 1 \mathrm{c}$ was positively correlated with the Gensini score $(\mathrm{r}=0.243, \mathrm{P}<0.05)$ among the whole studied population. Khaw et al., ${ }^{20}$ has also reported on the associationbetween $\mathrm{HbA1c}$ levels and major cardiovascular eventsand mortality. They reported that increasing levels ofHbA1c is associated with allcause and cardiovascular mortality. An increase of $1 \%$ in $\mathrm{HbA} 1 \mathrm{c}$ was associatedwith a $28 \%$ increase $(p<0.002)$ in the risk of death, independent of traditional cardiovascular risk factors. Interestingly, the association between increasing HbAlclevels and death persisted (hazard ratio 1.46; $\mathrm{p}=0.05$ )after individuals with $\mathrm{DM}$ and those with a $\mathrm{HbA} 1 \mathrm{c}$ levelabove $7 \%$ were excluded from the analysis, suggesting arole of $\mathrm{HbA} 1 \mathrm{c}$ assessment in risk stratification andprediction among individuals without DM. This was further supported by the results of Santos et al., ${ }^{21}$ meta-analysis of prospective cohorts. We didn't follow up patients to trace the incidence of cardiovascular mortality but all patients referred to coronary angiography had an acute coronary syndrome, i.e. cardiovascular event.

Eeg-Olofsson et al., ${ }^{22}$ conducted a study to analyze the association between $\mathrm{HbA} 1 \mathrm{c}$ and CVD in patients with type 2 diabetes in the Swedish National Diabetes Registry (NDR). This observational study included 18,334 patients (age 30-79years, previous CVD in $18 \%$, baseline HbA1c 5.0-10.9\%) who were followed for 6years (mean5.6 years) from 1997/1998 until 2003. Adjusted 6-year event rates increased with higher baseline or updated mean $\mathrm{HbA} 1 \mathrm{c}$ with no $\mathrm{J}$-shaped risk curves, in all patients and also when sub-grouping by shorter (mean 3years) or longer (mean 14years) diabetes duration, by presence or absence of previous CVD, orby treatment with oral hypoglycemic agents (OHAs) or insulin. Risk reductions of $20 \%$ for CAD and $16 \%$ for CVD $(\mathrm{P}<0.001)$ were found in patients with abaseline mean $\mathrm{HbA} 1 \mathrm{c}$ level of $6.5 \%$, compared to those with a mean level of $7.5 \%$. HbAlc was not associated with non-CVD mortality. This observational study showed progressively increasing risks of $\mathrm{CAD}, \mathrm{CVD}$ and total mortality with higher $\mathrm{HbAlc}$, and no risk increase at lowHbA1c levels even with longer diabetes duration, previous CVD or treatment with either insulin or OHAs. Patients achieving $\mathrm{HbA} 1 \mathrm{c}<7 \%$ showed benefits for risk reduction. Our study didn't include such a large number of patients being not a registry, but we included just non-diabetic patients and we were specifically 
targeting the CAD severity rather than the prevalence. The level of $\mathrm{HbAlc}$ measured was a single reading at time of presentation not a mean value over years.

Several studies were conducted to demonstrate the correlation between the level of $\mathrm{HbA1c}$ and the severity of CAD in non-diabetic patients. Study in the Sanjay Gandhi Postgraduate Institute of Medical Sciences Lucknow. ${ }^{23}$ India was done in 2011 and showed HbA1c in Non-diabetic Patients is an Independent Predictor of Coronary Artery Disease and its Severity: The total number of the screened patients is 1897 and 756 are excluded, the number of non-diabetic patients is 1141. The patients with CAD is 905 .

The conclusion of this study showed that in non-diabetic patients, higher $\mathrm{HbAlc}$ levels are significantly associated with CAD. This association is graded, continuous and is independent of conventional major cardiovascular risk factors. Elevated HbA1c is also strongly correlated with disease severity and higher SYNTAX score and $\mathrm{HbAlc}$ is a surrogate marker for chronic dysglycemia and could be utilized as an independent predictor of CAD and its severityeven in non-diabetic subjects.

Comparing this study to our study which includes 408 patients during just three months while this study includes 905 patients during one year, the other most important thing they defined significant of CAD as $>50 \%$ diameter in any vessel $>1.5 \mathrm{~mm}$ and the use of SYNTAX score which is an angiographic tool grading the complexity of coronary artery disease and obtain evidence based guidelines for selecting the optimal technique of revascularization (CABGor $\mathrm{PCI})^{24}$ not for assessing severity of CAD as Gensini score. In our study we estimated the severity of CAD in greater detail by using the Gensini score. Gensini ${ }^{17}$ suggested a scoring system which allocates anumerical value for the degree of stenosis in a coronary artery and a multiplication factor that depends on which coronary artery is involved and where the stenosis is locatedin the coronary artery. This provides a detailed assessment of CAD and does not ignore even very triviallesions in coronary arteries. Many other studies have used this scoring system to establish a correlation between the severity of CAD and other factors such as serum sodium level, ${ }^{25}$ renal impairment ${ }^{26}$ and impaired glucosetolerance. ${ }^{27}$ In the Study in the Sanjay Gandhi Postgraduate Institute of Medical Sciences Lucknow they divided the patients into four groups according to $\mathrm{HbA} 1 \mathrm{c}(\mathrm{HbA} 1 \mathrm{c}<5.5$, HbA1c 5.5-5.8, HbA1c 5.8-6.1, HbA1c >6.1). In our study the study population was stratified into high risk group (HbAlc $5.7-6.4 \%$ ) and a low risk group $(\mathrm{HbA} 1 \mathrm{c}<5.7 \%)$ according to ADA.

In Ravipatiet al., ${ }^{11}$ study, coronary angiography was performed for 152 men and 163 women with DM (mean age $55 \pm 8$ years) because of chest pain. The mean $\mathrm{HbAlc}$ level was $6.66 \pm 0.58 \%$ in 132 patients with 0 -vessel CAD, $8.00 \pm 0.84 \%$ in 40 patients with 1 -vessel CAD, $8.83 \pm 1.45 \%$ in 76 patients with 2 -vessel CAD, and $10.40 \pm 2.28 \%$ in 67 patients with 3- or 4-vessel CAD. There wasa significant increasing trend of $\mathrm{HbA} 1 \mathrm{c}$ levels over the increasing number ofvessels with CAD $(p<0.0001)$. In our study we were more detailed regarding assessment of the CAD using the Gensini score. The increasing number of diseased vessel does not reflect the severity of the lesions and in turn does not reflect the atherosclerotic burden. Moreover, patients without CAD represented $42 \%$ of the studied group but in our study we did not include patients with normal coronary angiograms.

In a recent study conducted by Department of Cardiology, Ankara Penal Institution Campus State Hospital, Ankara published in July $2013,{ }^{28} 65$ patients were included (11 females, mean age: $57 \pm 11.42$ years; 54 males, mean age: $54.56 \pm 8.51$ years) who were diagnosed as acute myocardial infarction without diabetes mellitus.
During hospitalization, fasting blood glucose, postprandial blood glucose and $\mathrm{HbA} 1 \mathrm{C}$ were measured in each patient. Gensini score was used to assess the severity of coronary artery disease. Twenty patients (30.8\%) had hypertension, 15 (23.1\%) had impaired fasting glucose, $10(15.3 \%)$ had combined impaired fasting and postprandial glucose, 28 had a low HDL cholesterol (45\%), and 30 (46\%) had abdominal obesity. Coronary angiography revealed one-vessel disease in 13 patients (20\%), and two- and three-vessel disease in 52 patients $(80 \%)$. There were no significant differences in terms of high-sensitive C-reactive protein (hs-CRP), total cholesterol, fasting glucose, and postprandial glucose $(0.068,0.974,0.178$, and 0.677 , respectively). There was no significant relation between the Gensini score and HbA1c levels ( $p=0.299)$, but there was a significant relation between the Gensini score and obesity $(\mathrm{p}=0.024)$. So this study concluded that, no significant relationship could be determined between the Gensini score and $\mathrm{HbA1C}$, fasting and postprandial blood glucose levels, lipid profile, and hs-CRP levels in patients with non-diabetic ACSs. However these results could be explained by small number of patients studied.

In our study, we included a larger number of patients ( 328 patients vs. 78 patients) and this might have an influence on their conflicting results, and the clinical presentations for coronary angiography were variable (not only acute myocardial infarction). We reclassified the studied group into high and low risk groups (based on HbAlc level) to demonstrate if there are statistical differences among two groups. What is also unique to our study is the use of different parameters of obesity including waist circumference, BMI and waist height ratio to identify correlations with the HbAlc level. RWMSI and serum Creatinine were first to be used as studied variables. They subdivided the CAD into single, two and three vessel disease and measure (hsCRP), in our study we subdivided CAD according to Gensini score $<30$ or $>30$ and take all CAD starting Gensini from 1 to 192 to evaluate accurately CAD. So that study showed only there was a significant relation between the Gensini score and obesity $(\mathrm{p}=0.024)$ in MI,but in our study we showed the level of $\mathrm{HbAlc}$ to be positively correlated with Gensini score $(\mathrm{r}=0.243, \mathrm{P}<0.000)$ and RWMSI $(\mathrm{r}=0.103, \mathrm{p}=0.038)$ and negatively correlated with $\operatorname{LVEF}(\mathrm{r}=-0.146$, $\mathrm{p}=0.003)$. Patients with Gensini score $>30$ has higher values of HbAlc, Gensini $>30$ the HbAlc $=6 \pm 0.51$ and Gensini $<30$ the $H b A 1 c=5.75 \pm 0.54(p<0.05, C I=95 \%)$.

Santos-Oliveira et al., ${ }^{21}$ investigated 16 datasets (nine for total cardiovascular events and seven for death) from five papers with 44, 158 patients (44\% men) over 404, 899 patient-years of followup. There were 1,366 cardiovascular deaths $(3.1 \% ; 3.37 / 1,000$ person-years) and 2, 142 cardiovascular events (4.9\%; 5.29/1,000 person-years). The overall meta-analytic $\beta$ coefficients were 0.720 (95\% CI $0.307-1.133)$ and $0.757(95 \%$ CI $0.382-1.132)$ for cardiac death and events respectively. Compared with the baseline value of $4.27 \%$, HbAlc level of $5 \%$ was associated with a relative riskfor cardiovascular death of 1.13 (95\% CI 1.05-1.21), a 6\%value with 1.34 (95\% CI 1.13-1.58), and a 7\% HbAlcwith relative risk 1.58 (95\% CI 1.22-2.06). Results for totalcardiovascular events were similar. Thus HbA1c was significantly associated with cardiovascular events anddeaths in persons without diabetes.

Rivera et al., ${ }^{29}$ even studied the association between increasing levels of HbA1c in a symptomatic individuals without DM and coronary plaque characteristics. The final study population consisted of 906 individuals without DM (mean age: $49 \pm 9$ years, $62 \%$ males); 19 and $9 \%$ of the population had any and two or more segments with coronary plaque, respectively. Unadjusted analysis showed a positive association between increasing levels of $\mathrm{HbAlc}$ and the number of 
coronary segments with any $(\mathrm{p}<0.001)$ and with mixed coronary plaques $(p<0.0001)$. The association persisted even when traditional risk factors were taken into account. No significant relationship was found between increasing $\mathrm{HbAlc}$ levels and the burden of noncalcified or calcified plaque. Thus increasing levels of HbAlc in a symptomatic individuals with out DM were associated with the presence of coronary atherosclerosis, but more specifically with the presence and burden of mixed coronary plaques. Our study included a fewer number of patients (408 patients). They were symptomatic and indicated for coronary angiography and not multi-detector computed tomography (MDCT). We did not demonstrate the number of plaques involved or the complexity of the atherosclerotic plaques, rather, we assessed the severity of the lesions.

In our study, we found that there is significant correlation between the level of HbAlc and Gensini score $(r=0.243, \mathrm{P}<0.000)$. Moreover, high risk patients (HbA1c between 5.7\% and 6.4\%) had lower LVEF and higher RWMSI adding to their risk profile inspite of having comparable gender distribution and laboratory findings as those with lower $\mathrm{HbA} 1 \mathrm{c}$ levels. This could be explained by increased prevalence of STEMI in the high risk group.

These results suggest that $\mathrm{HbAlc}$ in non-diabetic patients may be an indicator of metabolic alterations that could develop into cardiovascular events, including disease-specific mortality. There was no significant correlation between the level of $\mathrm{HbAlc}$ and total cholesterol, LDL, triglycerides and HDL levels. But there was significant correlation with Gensini score and total cholesterol $(\mathrm{r}$ $=0.098, \mathrm{p}=0.048), \operatorname{LDL}(\mathrm{r}=0.108, \mathrm{p}=0.029)$ and $\operatorname{HDL}(\mathrm{r}=0.131$, $\mathrm{p}=0.008$ ).

The correlation between Gensini score and FPG was insignificant $(\mathrm{r}$ $=0.088, p<0.076)$. In Yu Kataoka et al.,$^{30}$ study, FPG was a significant predictor of ALL $>20 \mathrm{~mm}$ by univariate analysis, which showed the impact of FPG level at time of presentation for coronary angiography and the severity of CAD. However, the prognostic value of FPG in non-diabetic adults was inferior to $\mathrm{HbAlc}$ level for identifying adults at risk for diabetes or CVD. ${ }^{9} \mathrm{HbA} 1 \mathrm{c}$ remained associated with CVD and death even after accounted for baseline FPG levels; in contrast, FPG was not significantly associated after adjustment for the HbAlc value.

Gensini score was also positively correlated with RWMSI ( $=0.272, \mathrm{p}<0.05)$ and negatively correlated with LVEF $(\mathrm{r}=-0.240$, $\mathrm{p}<0.05$ ). To our knowledge, this is the first study to demonstrate these correlations. The above mentioned studies assessed the severity of $\mathrm{CAD}$ and its correlation with $\mathrm{HbAlc}$ didn't include echocardiographic data among the studied variables in non-diabetic patients. Loeblein et al. ${ }^{31}$ retrieved the data of 140 consecutive patients who under went CABG between 1/2008-10/2008 to study the association between cardiovascular risk factors age, BMI, total cholesterol, HDL, LDL, TGs, Hb1Ac, hypertension, positive family history for CVD and history of smoking and syntax score, EF and BNP level. There was no association between Syntax score and cardiovascular risk factors. There was also no association between Syntax score and EF and between Syntax score and BNP. In our study, we found a significant correlation between the level of HbA1c and LVEF $(r=-0.146, p=0.003)$ and RWMSI $(\mathrm{r}=0.103, p=0.038)$. In contrst to H. Lobleinet al. ${ }^{31}$ we used the Gensini score and not the Syntax score and the results were conflicting regarding the correlation with EF. This might be due to the fact that Syntax score is a tool currently used in angiographic grading the complexity of CAD in order to select the optimal technique of revascularization rather assessment of the severity of CAD.

\section{Impact of HbA Ic in patients with ACS}

The study group was divided into two subgroups, the first group was STEMI group and the other one was the patients without STEMI which include (NSTEMI and unstable angina). Patients with STEMI about 126 which were $30.9 \%$ from total study group. The second group was 282 patients which is $69.1 \%$. In STEMI group the HbA1c showed only significant correlation with RWMSI $(\mathrm{r}=0.183, \mathrm{P}=0.04)$ and no correlation between $\mathrm{HbA} 1 \mathrm{c}$ and $\mathrm{EF}(-0.114, \mathrm{p}=0.206)$ or Gensini score $(\mathrm{r}=0.090, \mathrm{p}=0.318)$. In this group the Gensini score showed negative correlation with $\mathrm{EF}(\mathrm{r}=-0.208, \mathrm{p}=0.020)$ and positive correlation with RWMSI $(\mathrm{r}=0.243, \mathrm{p}=0.006)$. The second group showed the HbA1c significantly correlated negatively with $\mathrm{EF}(\mathrm{r}=-0.221, \mathrm{p}=<0.000)$ and positively with Gensini score $(\mathrm{r}=0.326, \mathrm{p}<0.000)$ and non-significant correlation with RWMSI $(0.063, \mathrm{P}=0.290)$. In this group the Gensini score showed significant negative correlation with EF $(r=-0.270$, $\mathrm{p}<0.000)$, and positive significant correlation with RWMSI $(\mathrm{r}=0.242$, $\mathrm{P}=<0.000)$.

In Ankara Penal Institution Campus State Hospital, Ankara published in July $2013,{ }^{28}$ they included 65 patients ( 11 females, mean age: $57 \pm 11.42$ years; 54 males, mean age: $54.56 \pm 8.51$ years) who were diagnosed as acute myocardial infarction without diabetes mellitus. So this study concluded that, no significant relationship could be determined between the Gensini score and $\operatorname{HbA1C}(\mathrm{p}=0.299)$, fasting and postprandial blood glucose levels, lipid profile, and hs-CRP levels in patients with non-diabetic ACSs, but showed only there was a significant relation between the Gensini score and obesity $(\mathrm{p}=0.024)$. STEMI groupin our study showed significant correlation between HbA1c and RWMSI ( $\mathrm{r}=0.183, \mathrm{P}=0.04)$ and no correlation between HbA1c and EF (-0.114, $p=0.206)$ or Gensini score $(r=0.090, p=0.318)$. But the second group showed the HbAlc significantly correlated negatively with $\mathrm{EF}(\mathrm{r}=-0.221, \mathrm{p}=<0.000)$ and positively with Gensini score $(\mathrm{r}=0.326, \mathrm{p}<0.000)$ and non-significant correlation with RWMSI $(0.063, \mathrm{P}=0.290)$. In STEMI group no significant correlation between Gensini and EF and this is explained by the adverse effect of STEMI that affect EF regardless severity of CAD. However in the second group there was strong relation between Gensini score and EF.

In observational study ${ }^{32}$ for impact of admission glycemia and glycosylated hemoglobin A1c on long-term clinical outcomes of non-diabetic patients with acute coronary syndrome, 452 consecutive non-diabetic patients with ACS who underwent PCI between January 1997 and December 2006. The patients were assigned to four groups according to the median values of admission glucose and HbAlc. The primary endpoint comprising a composite of all-cause death and nonfatal MI was compared among the four groups. The primary endpoint occurred in $13.3 \%$ of the participants during a median follow-up period of $4.7 y e a r s$. The cumulative incidence rate of primary endpoint significantly differed among the groups $(\mathrm{p}=0.048)$. Multivariable Cox regression analysis showed that the combination of elevated admission glucose and $\mathrm{HbAlc}$ was independently associated with long-term clinical outcomes. So this study concluded that combined admission glucose and $\mathrm{HbAlc}$ values were independently associated with clinical outcomes in non-diabetic patients with ACS treated with PCI.In our study we assessed the severity of CAD and the clinical outcome, in this study follow up the patients for 4.7 years for primary end point. The two studies searched in HbAlc in non-diabetic patients with ACS.

A systematic review and meta-analysis study ${ }^{33}$ regarding prognostic significance of hemoglobin A1Clevel in patients hospitalized with coronary artery disease was conducted in which systematic search of electronic databases (PubMed, EMBASE, OVID, Web of Science, and 
The Cochrane Library) for studies published from 1970 to May 2011. Cohort, case-control studies, andrandomized controlled trials that examined the effect of $\mathrm{HbA1c}$ on all-cause mortality were included. Twenty studies met final inclusion criteria (total $n=13,224$ ). From the pooled analyses, elevated $\mathrm{HbAlc}$ level was significantly associated with increased short-term (OR 2.32, 95\% CI, 1.61 to 3.35) and long-term (OR $1.54,95 \%$ CI, 1.23 to 1.94 ) mortality risk. Subgroup analyses suggested elevated $\mathrm{HbA} 1 \mathrm{c}$ level predicted higher mortality risk in patients without diabetes (OR 1.84, 95\% CI, 1.51 to 2.24). In contrast, in patients with diabetes, elevated $\mathrm{HbA} 1 \mathrm{c}$ level was not associated with increased risk of mortality (OR $0.95,95 \%$ CI, 0.70 to 1.28 ). In a risk-adjusted sensitivity analyses, elevated $\mathrm{HbA} 1 \mathrm{c}$ was also associated with a significantly high risk of adjusted mortality in patients without diabetes (adjusted OR 1.49, 95\% CI, 1.24 to 1.79), but had a borderline effect in patients with diabetes (adjusted OR 1.05, $95 \%$ CI, 1.00 to 1.11). The study concluded that elevated HbA1c level is an independent risk factor for mortality in CAD patients without diabetes, but not in patients with established diabetes. Prospective studies should further investigate whether glycemic control might improve outcomes in CAD patients without previously diagnosed diabetes. The most studies searched in the HbAlc in non-diabetic patients and adverse outcome, but our study and little other studies searched in $\mathrm{HbA} 1 \mathrm{c}$ in the non-diabetic and severity of the CAD. It is worth noting that most studies regarding $\mathrm{HbAlc}$ in non-diabetic evaluated its impact on outcome, however limited studies including ours, studied correlation between HbA1c and severity of CAD.

\section{Conclusion and recommendations}

HbAlc level is a useful marker and has a prognostic value to predict the severity of CAD among non-diabetic patients. It may be used as a cardiac marker in risk stratification of non-diabetic patients presenting with acute coronary syndrome and indicated for coronary angiography. Transthoracic echocardiography including estimation of LVEF and RWMSI should be used routinely prior to coronary angiography and may be used as predictors of severity of CAD. Therapeutic strategy to specifically lower the HbAlc level in nondiabetics still remain uncertain, randomized controlled clinical trials need to be done in this direction. ${ }^{33-199}$

\section{Acknowledgments}

None.

\section{Conflicts of interest}

Author declares there are no conflicts of interest.

\section{Funding}

None.

\section{References}

1. Butler WJ, Ostrander LD Jr, Carman WJ, et al. Mortality from coronary heart disease in the Tecumseh Study: long-term effect of diabetes mellitus, glucose tolerance and other risk factors. Am J Epidemiol. 1985;121(4):541-547

2. Klein R. Hyperglycemia and microvascular and macrovascular disease in diabetes. Diabetes Care. 1995;18(2):258-268.

3. Nasir K, Santos RD, Tufail K, et al. High normal fasting blood glucose in non-diabetic range is associated with increased coronary arery calcium burden in asymptomatic men. Atherosclerosis. 2007;195(2):e155-e160.

4. Khaw KT, Wareham N, Luben R, et al. Glycated hemoglobin, diabetes and mortality in men in Norfolk cohort of European Prospective
Investigation of Cancer and Nutrition (EPIC-Norfolk). BMJ. 2001;322(7277):15-18.

5. Lee HJ, Her SH, Im YS, et al. Significance of Inflammatory Markers in Diabetic Patients with Stable Coronary Artery Disease. Korean J Intern Med. 2009;24(3):212-219.

6. Selvin E, Crainiceanu CM, Brancati FL, et al. Short-term variability in measures of glycemia and implications for the classification of diabetes. Arch Intern Med. 2007;167(14):1545-1551.

7. American Diabetes Association. Diagnosis and classification of diabetes mellitus. Diabetes Care. 2010;33(Suppl 1):S62-S69.

8. Meigs JB, Nathan DM, Cupples LA, et al. Tracking of Glycated hemoglobin in the original cohort of the Framingham Heart Study. $J$ Clin Epidemiol. 1996;49(4):411-417.

9. Selvin E, Steffes MW, Zhu H, et al. Glycated Hemoglobin, diabetes, and Cardiovascular risk in Nondiabetic Adults. $N$ Engl $\mathrm{J}$ Med . 2010;362:800-811.

10. Selvin E, Coresh J, Shahar E, et al. Glycemia (haemoglobin A1c) and incident of ischemic stroke: the Atherosclerosis Risk in Communities (ARIC) study. Lancet Neurol. 2005;4(12):821-826.

11. Ravipati G, Aronow WS, Ahn C, et al. Association of hemoglobin A1c level with the severity of coronary artery disease in patients with diabetes mellitus. Am J Cardiol. 2006;97(7):968-969.

12. Selvin E, Wattanakit K, Steffens MW, et al. HbA1c and peripheral arterial disease in diabetes: the Atherosclerosis Risk in Communities study. Diabetes Care. 2006;29(4):877-882.

13. Engoren M, Habib RH, Zacharias A, et al. The prevalence of elevated hemoglobin A1c in patients undergoing coronary artery bypass surgery. J Cardiothorac Surg . 2008;3:63.

14. Stakos DA, Schuster DP, Sparks EA, et al. Association between glycosylated hemoglobin, left ventricular mass and aortic function in nondiabetic individuals with insulin resistance. Eur $J$ Endocrinol. 2007;157(1):63-68.

15. The Seventh Report of the Joint National Committee on Prevention, Detection, Evaluation and Treatment of High Blood Pressure (JNC7). Hypertension. 2003;42:1206.

16. Clinical Guidelines on the Identification, Evaluation, and Treatment of Overweight and Obesity in Adults. National Heart, Lung, and Blood Institute, USA. 1998;

17. Gensini GG. A more meaningful scoring system for determining the severity of coronary heart disease. Am J Cardiol. 1983;51(3):606

18. Sesso HD, Lee IM, Gaziano JM, et al. Maternal and paternal history of myocardial infarction and risk of cardiovascular disease in men and women. Circulation. 2001;104(4):393-398.

19. Gardin JM, Adams DB, Douglas PS, et al. Recommendations for A Standardized Report For Adult Transthoracic Echocardiography. From the American Society of Echocardiography's Nomenclature and Standards Committee and Task Force for a Standardized Echocardiography Report. J Am Soc Echocardiogr. 2002;15(3):275-290.

20. Khaw KT, Wareham N, Bingham S, et al. Association of hemoglobin A1c with cardiovascular disease and mortality in adults: the European prospective investigation into cancer in Norfolk. Ann Intern Med. 2004;141(6):413-420.

21. Han TS, van Leer EM, Seidell JC, et al. Waist circumference action levels in the identification of cardiovascular risk factors: prevalence study in a random sample. BMJ . 1995;311 (7017):1401-1405.

22. Santos-Oliveira R, Purdy C, da Silva MP, et al. Haemoglobin A1c levels and subsequent cardiovascular disease in persons without diabetes: a meta-analysisof prospective cohorts. Diabetologia. 2011;54(6):1327-1334. 
23. Przemysław W, Grzegorz Z, Maria M, et al. Cushing's disease assessing the efficacy of transsphenoidal surgery. Endokrynologia Polska . 2012;63(5):398-404.

24. Sianos G, Morel MA, Kappetein AP, et al. The SYNTAX Score: an angiographic tool grading the complexity of coronary artery disease. EuroIntervention. 2005;1(2):219-227.

25. Jia E, Yang Z, Zhu TB, et al. Serum sodium concentration is significantly associated with the angiographic characteristics of coronary atherosclerosis. Acta Pharmacol Sin. 2007;28(8):1136-1142.

26. Cay S, Metin F, Korkmaz S. Association of renal functional impairment and the severity of coronary artery disease. Anadolu Kardiyol Derg. 2007;7(1):44-48.

27. Kataoka Y, Yasuda S, Morii I, et al. Quantitative coronary angiographic studies of patients with angina pectoris and impaired glucose tolerance. Diabetes Care. 2005;28(9):2217-2222.

28. Loeblein, Dzemali O, Köhn M, et al. Cardiovascular risk factors correlation with syntax score, ejection fraction and B-type natriuretic peptide. Cardiac surgery. 2011.

29. Ahmet Göktuğ Ertem, Hüseyin Bağbanc1, Harun Kılıç, et al. Relationship between $\mathrm{HbA} 1 \mathrm{c}$ levels and coronary artery severity in nondiabetic acute coronary syndrome patients. Türk Kardiyol Dern Arş - Arch Turk Soc Cardiol. 2013;41:389-395.

30. Rivera JJ, Choi EK, Yoon YE, et al. Association between increasing levels of hemoglobinA1c and coronary atherosclerosis in asymptomatic individuals without diabetes mellitus. Coron Artery Dis. 2010;21(3):157-163.

31. Eeg-Olofsson K, Cederholm J, Nilsson PM, et al. Glycemic control and cardiovascular disease in 7454 patients with type 1 diabetes: an observational study from the Swedish National Diabetes Register (NDR). Diabetes Care. 2010;33(7):1640-1646.

32. Sharma R, Pellerin D, Gaze DC, et al. Dobutamine stress echocardiography and the resting but not exercise electrocardiograph predict severe coronary artery disease in renal transplant candidates Nephrol Dial Transplant. 2005;20(10):2207-2214

33. Naito R, Miyauchi K, Ogita M, et al. Impact of admission glycemia and glycosylated hemoglobin A1c on long-term clinical outcomes of non-diabetic patients with acute coronary syndrome. J Cardiol. 2014;63(2):106-111.

34. Rohlfing CL, Little RR, Wiedmeyer HM, et al. Use of GHb (HbA1c) in screening for undiagnosed diabetes in the U.S. population. Diabetes Care. 2000;23(2):187-191.

35. International Expert Committee. International Expert Committee report on the role of the A1C assay in the diagnosis of diabetes: Diabetes Care 32(7): 1327-1334. Clin Biochem Rev . 2009;30(4):197-200.

36. Riccardi G, Vaccaro O, Rivellese A, et al. Reproducibility of the new diagnostic criteria for impaired glucose tolerance. Am J Epidemiol. $1985 ; 121(3): 422-429$

37. Cheng YJ, Gregg EW, Geiss LS, et al. Association of A1C and fasting plasma glucose levels with diabetic retinopathy prevalence in the U.S. population: Implications for diabetes diagnostic thresholds. Diabetes Care. 2009;32(11):2027-2032.

38. Bunn HF, Haney DN, Gabbay KH, et al. Further identification of the nature and linkage of the carbohydrate in hemoglobin A1c. Biochem Biophys Res Commun. 1975;67(1):103-109.

39. Nathan DM, Singer DE, Hurxthal K, et al. The clinical information value of the glycosylated hemoglobin assay. $N$ Engl $J$ Med. 1984;310(6):341-346

40. Goldstein DE. Is glycosylated hemoglobin clinically useful? $N$ Engl J Med. 1984;310(6):384-385.
41. Rohlfing CL, Wiedmeyer HM, Little RR, et al. Defining the relationship between plasma glucose and HbA1c: analysis of glucose profiles and $\mathrm{HbA} 1 \mathrm{c}$ in the Diabetes Control and Complications trial. Diabetes Care. 2002;25(2):275-278.

42. Nathan DM, Turgeon H, Regan S. Relationship between glycated haemoglobin levels and mean glucose levels over time. Diabetologia. 2007;50(11):2239-2244.

43. Nathan DM, Turgeon H, Regan S. Relationship between glycated haemoglobin levels and mean glucose levels over time. Diabetologia. 2007;50(11):2239-2244

44. Nathan DM1, Kuenen J, Borg R, et al. Translating the A1C assay into estimated average glucose values. Diabetes Care. 2008;31(8):1473-1478.

45. Little RR, Wiedmeyer HM, England JD, et al. Interlaboratory comparison of glycohemoglobin results: College of American Pathologists Survey data. Clin Chem . 1991;37(10 pt 1):1725-1729.

46. Steffes MW, Sacks DB. Measurement of circulating glucose concentrations: the time is now for consistency among methods and types of samples. Clin Chem. 2005;51(9):1569-1570.

47. Hanas R, John G. 2010 consensus statement on the worldwide standardization of the hemoglobin A1C measurement. Diabetes Care. 2010;33(8):1903-1904.

48. National Glycohemoglobin Standardization Program (NGSP) website, which contains up to date information about substances that interfere with Glycohemoglobin (HbAlc) test results (2016).

49. Brown JN, Kemp DW, Brice KR. Class effect of erythropoietin therapy on hemoglobin $\mathrm{A}(1 \mathrm{c})$ in a patient with diabetes mellitus and chronic kidney disease not undergoing hemodialysis. Pharmacotherapy. 2009;29(4):468-472.

50. Ng JM, Cooke M, Bhandari S, et al. The effect of iron and erythropoietin treatment on the $\mathrm{A} 1 \mathrm{C}$ of patients with diabetes and chronic kidney disease. Diabetes Care. 2010;33(11):2310-2313.

51. Roberts WL, Safar-Pour S, De BK, et al. Effects of hemoglobin C and $\mathrm{S}$ traits on glycohemoglobin measurements by eleven methods. Clin Chem. 2005;51(4):776-778.

52. Herman WH, Dungan KM, Wolffenbuttel BH, et al. Racial and ethnic differences in mean plasma glucose, hemoglobin A1c, and 1,5-anhydroglucitol in over 2000 patients with type 2 diabetes. $J$ Clin Endocrinol Metab. 2009;94(5):1689-1694.

53. Cohen RM, Franco RS, Khera PK, et al. Red cell life span heterogeneity in hematologically normal people is sufficient to alter HbA1c. Blood. 2008;112(10):4284-4291.

54. Lloyd-Jones DM, Larson MG, Beiser A, et al. Lifetime risk of developing coronary heart disease. Lancet . 1999;353(9147):89-92.

55. Chobanian AV, Bakris GI, Black HR, et al. Joint National Committee on Prevention, Detection, Evaluation and Treatment of High Blood Pressure; National Heart, Lung and Blood Institute; National High Blood Pressure Education Program Coordinating Committee. Seventh Report of the Joint National Committee on Prevention, Detection, Evaluation, and Treatment of High Blood Pressure. Hypertension. 2003;42:1206-1252.

56. Clive Rosendorff, Henry Black R, Christopher Canon C, et al. A Scientific Statement From the American Heart Association Council for High Blood Pressure Research and the Councils on Clinical Cardiology and Epidemiology and Prevention. Hypertension. 2007;50:e28-e55.

57. Franklin SS, Larson MG, Khan SA, et al. Does the relation of blood pressure to coronary heart disease risk change with aging? The Framingham Heart Study. Circulation. 2001;103(9):1245-1249.

58. Lewington S, Clarke R, Qizilbash N, et al. Age-specific relevance of usual blood pressure tovascular mortality: a meta-analysis of individual data for one million adults in 61 prospective studies. Lancet. 2002;360(9349):1903-1913. 
59. HC 23-I. Authority of the House of Commons London: The International Obesity Task Force. 2004

60. Clinical Guidelines on the Identification, Evaluation, and Treatment of Overweight and Obesity in Adults-the Evidence Report. National Institutes of Health. Obes Res. 1998;6(Suppl 2):51S-209S.

61. Bosello O, Zamboni M. Visceral obesity and metabolic syndrome. Obes Rev. 2000;1(1):47-56.

62. Abate N, Garg A, Peshock RM, et al. Relationships of generalized and regional adiposity to insulin sensitivity in men. J Clin Invest. 1995;96(1):88-98.

63. Abate N, Garg A, Peshock RM, et al. Relationship of generalized and regional adiposity to insulin sensitivity in men with NIDDM. Diabetes. 1996;45(12):1684-1693.

64. National Cholesterol Education Program (NCEP) Expert Panel on Detection, Evaluation, and Treatment of High Blood Cholesterol in Adults (Adult Treatment Panel III). Third Report of the National Cholesterol Education Program (NCEP) Expert Panel on Detection, Evaluation, and Treatment of High Blood Cholesterol in Adults (Adult Treatment Panel III) final report. Circulation. 2002;106(25):3143-3421.

65. Grundy SM, Hansen B, Smith Jr SC, et al. Clinical management of metabolic syndrome: report of the American Heart Association/National Heart, Lung, and Blood Institute/American Diabetes Association conference on scientific issues related to management. Circulation 2004;109(4):551-556

66. Unwin N, Shaw J, Zimmet P, et al. Impaired glucose tolerance and impaired fasting glycaemia: the current status on definition and intervention. Diabet Med. 2002;19(9):708-723.

67. Ridker PM. High-sensitivity C-reactive protein and cardiovascular risk: rationale for screening and primary prevention. Am J Cardiol. 2003;92(4B):17K-22K.

68. Guerre-Millo M. Adipose tissue hormones. J Endocrinol Invest. 2002;25(10):855-861.

69. Hubert HB, Feinleib M, McNamara PM, et al. Obesity as an independent risk factor for cardiovascular disease:a 26-year follow-up of participants in the Framingham Heart Study. Circulation. 1983;67(5):968-977.

70. Rabkin SW, Mathewson FA, Hsu PH. Relation of body weight to development of ischemic heart disease in a cohort of young North American men after a 26 year observation period: the Manitoba Study. Am J Cardiol. 1977;39(3):452-458.

71. McGill HC Jr, McMahan CA, Herderick EE, et al. Origin of atherosclerosis in childhood and adolescence. Am J Clin Nutr. 2000;72(5 Suppl):1307S-1315S.

72. Eckel RH, Krauss RM. American Heart Association call to action: obesity as a major risk factor for coronary heart disease. AHA Nutrition Committee. Circulation. 1998;97(21):2099-2100.

73. Eckel RH. Obesity and heart disease: a statement for healthcare professionals from the Nutrition Committee, American Heart Association. Circulation. 1997;96(9):3248-3250.

74. Expert Panel on Detection, Evaluation, and Treatment of High Blood Cholesterol in Adults. Executive Summary of The Third Report of The National Cholesterol Education Program (NCEP) Expert Panel on Detection, Evaluation, And Treatment of High Blood Cholesterol In Adults (Adult Treatment Panel III). JAMA. 2001;285(19):2486-2497.

75. Austin MA. Epidemiology of hypertriglyceridemia and cardiovascular disease. Am J Cardiol. 1999;83(Suppl):13F-16F.

76. Expert Panel on Detection, Evaluation, and Treatment of High Blood Cholesterol in Adults. Executive summary of the third report of the National Cholesterol Education Program (NCEP). JAMA. 2001;285(19):2486-2497.
77. Maron DJ. The epidemiology of low levels of high-density lipoprotein cholesterol in patients with and without coronary artery disease. $\mathrm{Am} \mathrm{J}$ Cardiol . 2000;86(12A):11L-4L.

78. Assmann G, Schulte H, von Eckardstein A, et al. High-density lipoprotein cholesterol as a predictor of coronary heart disease risk: the PROCAM experience and pathophysiological implications for reverse cholesterol transport. Atherosclerosis. 1996;124(Suppl):S11-S20.

79. Summary of the second report of the National Cholesterol Education Program (NCEP) Expert Panel on Detection, Evaluation, and Treatment of High Blood Cholesterol in Adults (Adult Treatment Panel II) JAMA. 1993;269(23):3015-3023.

80. Hukkanen J, Jacob P 3rd, Benowitz NL. Metabolism and disposition kinetics of nicotine. Pharmacol Rev. 2005;57(1):79-115.

81. Kannel WB. Hypertension, blood lipids, and cigarette smoking as co-risk factors for coronary heart disease. Ann N Y Acad Sci. 1978;304:128-139.

82. McBride PE. The health consequences of smoking. Cardiovascular diseases. Med Clin North Am. 1992;76(2):333-353.

83. Lerner DJ, Kannel WB. Patterns of coronary heart disease morbidity and mortality in the sexes: a 26-year follow-up of the Framingham population. Am Heart J. 1986;111(2):383-390.

84. Kannel WB. Prevalence and clinical aspects of unrecognized myocardial infarction and sudden unexpected death. Circulation. 1987;75(3 Pt 2): II4-II5.

85. Gordon T, Kannel WB, Hjortland MC, et al. Menopause and coronary heart disease. The Framingham Study. Ann Intern Med. 1978;89(2):157-161.

86. Sarnak MJ, Levey AS, Schoolwerth AC, et al. Kidney disease as a risk factor for development of cardiovascular disease: a statement from the American Heart Association Councils on Kidney in Cardiovascular Disease, High Blood Pressure Research, Clinical Cardiology, and Epidemiology and Prevention. Circulation. 2003;108(17):2154-2169.

87. Ix JH, Shlipak MG, Liu HH,et al. Association between renal insufficiency and inducible ischemia in patients with coronary artery disease: the heart and soul study. J Am Soc Nephrol . 2003;14(12):3233-3238.

88. Muntner P, He J, Hamm L, et al. Renal insufficiency and subsequent death resulting from cardiovascular disease in the United States. $J$ Am Soc Nephrol. 2002;13(3):745-753.

89. Shlipak MG, Stehman-Breen C, Vittinghoff E, et al. Creatinine levels and cardiovascular events in women with heart disease: do small changes matter? Am J Kidney. 2004;43(1):37-44.

90. Gibson CM, Pinto DS, Murphy SA, et al. Association of creatinine and creatinine clearance on presentation in acute myocardial infarction with subsequent mortality. J Am Coll Cardiol . 2003;42(9):1535-1543.

91. Best PJ, Lennon R, Ting HH, et al. The impact of renal insufficiency on clinical outcomes in patients undergoing percutaneous coronary interventions. J Am Coll Cardiol. 2002;39(7):1113-1119.

92. Sosnov J, Lessard D, Goldberg RJ, et al. Differential symptoms of acute myocardial infarction in patients with kidney disease: a communitywide perspective. Am J Kidney Dis. 2006; 47(3):378-384.

93. Muntner P, He J, Hamm L, et al. Renal insufficiency and subsequent death resulting from cardiovascular disease in the United States. $J$ Am Soc Nephrol. 2002;13(3):745-753.

94. Foley RN, Murray AM, Li S, et al. Chronic kidney disease and the risk for cardiovascular disease, renal replacement, and death in the United States Medicare population, 1998 to 1999. J Am Soc Nephrol. 2005; 16(2):489-495.

95. Mahmoodi BK, Matsushita K, Woodward M, et al. Associations of kidney disease measures with mortality and end-stage renal disease in individuals with and without hypertension: a meta-analysis. Lancet. 2012;380(9854):1649-1661. 
96. Chronic Kidney Disease Prognosis Consortium, Matsushita K, van der Velde $\mathrm{M}$, et al. Association of estimated glomerular filtration rate and albuminuria with all-cause and cardiovascular mortality in general population cohorts: a collaborative meta-analysis. Lancet. 2010;375(9731):2073-2081.

97. Leoncini G, Viazzi F, Pontremoli R. Overall health assessment: a renal perspective. Lancet . 2010;375(9731):2053-2054.

98. Weiner DE, Tighiouart H, Elsayed EF, et al. The Framingham predictive instrument in chronic kidney disease. $J$ Am Coll Cardiol. 2007;50(3):217-224.

99. Garg AX, Clark WF, Haynes RB, et al. Moderate renal insufficiency and the risk of cardiovascular mortality: results from the NHANES I. Kidney Int. 2002;61(4):1486-1494.

100. Hallan S, Astor B, Romundstad S, et al. Association of kidney function and albuminuria with cardiovascular mortality in older vs younger individuals: The HUNT II Study. Arch Intern Med 2007;167(22):2490-2496.

101. Tonelli M, Muntner P, Lloyd A, et al. Using proteinuria and estimated glomerular filtration rate to classify risk in patients with chronic kidney disease: a cohort study. Ann Intern Med . 2011;154(1):12-21.

102. van der Velde M, Matsushita K, Coresh J, et al. Lower estimated glomerular filtration rate and higher albuminuria are associated with all-cause and cardiovascular mortality.A collaborative meta-analysis of high-risk population cohorts. Kidney Int. 2011;79(12):1341-1352.

103. Tonelli M, Muntner P, Lloyd A, et al. Risk of coronary events in people with chronic kidney disease compared with those with diabetes: a population-level cohort study. Lancet . 2002;380(9844):807-814.

104. Matsushita K, Selvin E, Bash LD, et al. Change in estimated GFR associates with coronary heart disease and mortality. J Am Soc Nephrol. 2009;20(12):2617-2624.

105. Schmieder RE, Mann JF, Schumacher H, et al. Changes in albuminuria predicts mortality and morbidity in patients with vascular disease. $J \mathrm{Am}$ Soc Nephrol. 2011;22(7):1353-1364.

106. Ueland PM, Refsum H. Plasma homocysteine, a risk factor for vascular disease: plasma levels in health, disease, and drug therapy. J Lab Clin Med. 1989;114(5):473-501.

107. McCully KS. Homocysteine and vascular disease. Nat Med. 1996;2(4):386-389.

108. Mezzano D, Muñoz X, Martínez C, et al. Vegetarians and cardiovascular risk factors: hemostasis, inflammatory markers and plasma homocysteine. Thromb Haemost. 1991;81(6):913-917.

109. Smulders YM, de Man AM, Stehouwer CD, et al. Trimethoprim and fasting plasma homocysteine. Lancet. 1998;352(9143):1827-1828.

110. Desouza C, Keebler M, McNamara DB, et al. Drugs affecting homocysteine metabolism: impact on cardiovascular risk. Drugs 2002;62(4):605-616.

111. Dierkes J, Westphal S, Luley C. The effect of fibrates and other lipidlowering drugs on plasma homocysteine levels. Expert Opin Drug Saf. 2004;3(2):101-111.

112. Bazzano LA, He J, Muntner P, et al. Relationship between cigarette smoking and novel risk factors for cardiovascular disease in the United States. Ann Intern Med. 2003;138(11):891-897.

113. Christen WG, Ajani UA, Glynn RJ, et al. Blood levels of homocysteine and increased risks of cardiovascular disease: causal or casual? Arch Intern Med. 2001;160(4):422-434.

114. Homocysteine Studies Collaboration. Homocysteine and risk of ischemic heart disease and stroke: a meta-analysis. JAMA. 2002;288(16):2015-2022
115. Humphrey LL, Fu R, Rogers K, et al. Homocysteine level and coronary heart disease incidence: a systematic review and meta-analysis. Mayo Clin Proc. 2008;83(11):1203-1212.

116. Al-Obaidi MK, Philippou H, Stubbs PJ, et al. Relationships between homocysteine, factor VIIa, and thrombin generation in acute coronary syndromes. Circulation. 2000;101(4):372-377.

117. Soinio M, Marniemi J, Laakso M, et al. Elevated plasma homocysteine level is an independent predictor of coronary heart disease events in patients with type 2 diabetes mellitus. Ann Intern Med. 2004;140(2): 94-100.

118. Genest JJ Jr, McNamara JR, Upson B, et al. Prevalence of familial hyperhomocyst(e)inemia in men with premature coronary artery disease. Arterioscler Thromb. 1991;11(5):1129-1136.

119. Nygård $\mathrm{O}$, Nordrehaug $\mathrm{JE}$, Refsum $\mathrm{H}$, et al. Plasma homocysteine levels and mortality in patients with coronary artery disease. $N$ Engl $J$ Med. 1997;337(4):230-236.

120. Schnyder G, Flammer Y, Roffi M, et al. Plasma homocysteine levels and late outcome after coronary angioplasty. J Am Coll Cardiol 2002;40(10):1769-1776.

121. Selhub J, Jacques PF, Bostom AG, et al. Association between plasma homocysteine concentrations and extracranial carotid-artery stenosis. $N$ Engl J Med . 1995;332(5):286-291.

122. Kelly PJ, Rosand J, Kistler JP, et al. Homocysteine, MTHFR 677C-->T polymorphism, and risk of ischemic stroke: results of a meta-analysis Neurology. 2002;59(4):529-536.

123. Boysen G, Brander T, Christensen H, et al. Homocysteine and risk of recurrent stroke. Stroke. 2003;34(5):1258-1261.

124. Kim NK, Choi BO, Jung WS, et al. Hyperhomocysteinemia as an independent risk factor for silent brain infarction. 2003;61(11):1595-1599.

125. Vasan RS, Beiser A, D'Agostino RB, et al. Plasma homocysteine and risk for congestive heart failure in adults without prior myocardial infarction. JAMA. 2003;289(10):1251-1257.

126. US Department of Health and Human Services. 2008 physical activity guidelines for Americans. 2008.

127. Powell KE, Thompson PD, Caspersen CJ, et al. Physical activity and the incidence of coronary heart disease. Annu Rev Public Health. $1987 ; 8: 253-287$

128. Lemaitre RN, Siscovick DS, Raghunathan TE, et al. Leisure-time physical activity and the risk of primary cardiac arrest. Arch Intern Med. 1999;159(7):686-690.

129. Shiroma EJ, Lee IM. Physical activity and cardiovascular health: lessons learned from epidemiological studies across age, gender, and race/ ethnicity. Circulation . 2010;122(7):743-752.

130. Reddigan JI, ArdernCI, Riddell MC, et al. Relation of physical activity to cardiovascular disease mortality and the influence of cardiometabolic risk factors. Am J Cardiol . 2011;108(10):1426-1431.

131. Fletcher GF, Balady G, Blair SN, et al. Statement on exercise: benefits and recommendations for physical activity programs for all Americans. A statement for health professionals by the Committee on Exercise and Cardiac Rehabilitation of the Council on Clinical Cardiology, American Heart Association. Circulation. 1996;94(4):857-862.

132. Fletcher GF, Balady G, Froelicher VF, et al. Exercise standards. A statement for healthcare professionals from the American Heart Association. Writing Group. Circulation. 1995;91(2):580-615.

133. Blair SN, Kohl HW 3rd, Paffenbarger RS Jr, et al. Physical fitness and all-cause mortality. A prospective study of healthy men and women. JAMA. 1989;262(17):2395-2401. 
134. Leon AS, Connett J, Jacobs DR Jr, et al. Leisure-time physical activity levels and risk of coronary heart disease and death. The Multiple Risk Factor Intervention Trial. JAMA.1987; 258(17):2388-2395.

135. Manson JE, Hu FB, Rich-Edwards JW, et al. A prospective study of walking as compared with vigorous exercise in the prevention of coronary heart disease in women. N Engl J Med. 1999; 341(9):650-658.

136. Yusuf S, Hawken S, Ounpuu S, et al. Effect of potentially modifiable risk factors associated with myocardial infarction in 52 countries (the INTERHEART study): case-control study. Lancet. 2004;364(9438):937-952.

137. Clark AM, Hartling L, Vandermeer B, et al. Meta-analysis: secondary prevention programs for patients with coronary artery disease. Ann Intern Med. 2005;143(9):659-672.

138. Wannamethee SG, Shaper AG, Walker M. Physical activity and mortality in older men with diagnosed coronary heart disease. Circulation. 2000;102(12):1358-1363.

139. Graham I, Atar D, Borch-Johnsen K, et al. European guidelines on cardiovascular disease prevention in clinical practice: executive summary: Fourth Joint Task Force of the European Society of Cardiology and Other Societies on Cardiovascular Disease Prevention in Clinical Practice (Constituted by representatives of nine societies and by invited experts). Eur Heart J . 2007;28(19):2375-2414.

140. Pate RR, Pratt M, Blair SN, et al. Physical activity and public health. A recommendation from the Centers for Disease Control and Prevention and the American College of Sports Medicine. JAMA. 1995;273(5):402-407.

141. Otaki Y, Gransar H, Berman DS, et al. Impact of family history of coronary artery disease in young individuals (from the CONFIRM registry). Am J Cardiol . 2013;111(8):1081-1086.

142. Berg AO, Baird MA, Botkin JR, et al. National Institutes of Health Stateof-the-Science Conference Statement: Family History and Improving Health. Ann Intern Med. 2009;151(12):872-877.

143. Andresdottir MB, Sigurdsson G, Sigvaldason H, et al. Fifteen percen of myocardial infarctions and coronary revascularizations explained by family history unrelated to conventional risk factors. The Reykjavik Cohort Study. Eur Heart J. 2002;23(21):1655-1663.

144. Lloyd-Jones DM, Nam BH, D'Agostino RB Sr, et al. Parental cardiovascular disease as a risk factor for cardiovascular disease in middle-aged adults: a prospective study of parents and offspring. JAMA. 2004;291(18):2204-2211.

145. Sivapalaratnam S, Boekholdt SM, Trip MD, et al. Family history of premature coronary heart disease and risk prediction in the EPIC Norfolk prospective population study. Heart. 2010; 96(24):1985-1989.

146. Ranthe MF, Carstensen L, Oyen N, et al. Family history of premature death and risk of early onset cardiovascular disease. J Am Coll Cardiol 2012;60(9):814-821.

147. Zöller B, Li X, Sundquist J, et al. Multiplex sibling history of coronary heart disease is a strong risk factor for coronary heart disease. Eur Heart J. 2012;33(22):2849-2855.

148. Qureshi N, Armstrong S, Dhiman P, et al. Effect of adding systematic family history enquiry to cardiovascular disease risk assessment in primary care: a matched-pair, cluster randomized trial. Ann Intern Med. 2012;156(4):253-262

149. Faxon DP, Fuster V, Libby P, et al. Atherosclerotic Vascular Disease Conference: Writing Group III: pathophysiology. Circulation 2004;109(21):2617-2625

150. Libby P, Ridker PM, Hansson GK. Progress and challenges in translating the biology of atherosclerosis. Nature. 2011;473(7347):317-325.

151. Tuzcu EM, Kapadia SR, Tutar E, et al. High prevalence of coronary atherosclerosis in asymptomatic teenagers and young adults: evidence from intravascular ultrasound. Circulation . 2001;103(22):2705-2710.
152. McGill HC Jr, McMahan CA, Zieske AW, et al. Association of Coronary Heart Disease Risk Factors with microscopic qualities of coronary atherosclerosis in youth. Circulation. 2000; 102(4):374-379.

153. Strong JP, Malcom GT, McMahan CA, et al. Prevalence and extent of atherosclerosis in adolescents and young adults: implications for prevention from the Pathobiological Determinants of Atherosclerosis in Youth Study. JAMA. 1999;281(8):727-735.

154. van Dijk RA, Virmani R, von der Thüsen JH, et al. The natural history of aortic atherosclerosis: a systematic histopathological evaluation of the peri-renal region. Atherosclerosis. 2010;210(1):100-106.

155. Davies MJ, Woolf N, Rowles PM, et al. Morphology of the endothelium over atherosclerotic plaques in human coronary arteries. Br Heart $J$. 1988;60(6):459-464.

156. Sata M, Saiura A, Kunisato A, et al. Hematopoietic stem cells differentiate into vascular cells that participate in the pathogenesis of atherosclerosis. Nat Med. 2002;8(4):403-409.

157. O’Brien KD, Olin KL, Alpers CE, et al. Comparison of apolipoprotein and proteoglycan deposits in human coronary atherosclerotic plaques: colocalization of biglycan with apolipoproteins. Circulation. 1998;98(6):519-527.

158. Kockx MM, De Meyer GR, Muhring J, et al. Apoptosis and related proteins in different stages of human atherosclerotic plaques. Circulation. 1998;97(23):2307-2315.

159. Heistad DD, Marcus ML, Larsen GE, et al. Role of vasa vasorum in nourishment of the aortic wall. Am J Physiol. 1981;240(5):H781-H787.

160. Barger AC, Beeuwkes R 3rd, Lainey LL, et al. Hypothesis: vasa vasorum and neovascularization of human coronary arteries. A possible role in the pathophysiology of atherosclerosis. $N$ Engl J Med. 1984;310(3):175-177.

161. Kolodgie FD, Gold HK, Burke AP, et al. Intraplaque hemorrhage and progression of coronary atheroma. $N$ Engl $J$ Med. 2003;349(24):2316-2325.

162. Stary HC, Chandler AB, Dinsmore RE, et al. A definition of advanced types of atherosclerotic lesions and a histological classification of atherosclerosis. A report from the Committee on Vascular Lesions of the Council on Arteriosclerosis, American Heart Association. Circulation. 1995;92(5):1355-1374.

163. Schoenhagen P, Ziada KM, Vince DG, et al. Arterial remodeling and coronary artery disease: the concept of "dilated" versus "obstructive" coronary atherosclerosis. J Am Coll Cardiol. 2001;38(2):297-306.

164. Schoenhagen P, Ziada KM, Kapadia SR, et al. Extent and direction of arterial remodeling in stable versus unstable coronary syndromes: an intravascular ultrasound study. Circulation. 2000;101(6):598-603.

165. Marc S. Angiographic image analysis to assess the severity of coronary stenosis. Twente University Press, the Netherlands. Califf RM, Phillips HR 3rd, Hindman MC, Mark DB, Lee KL, et al. (1985) Prognostic Value of a Coronary Artery Jeopardy Score. J Am Coll Cardiol. 2002;5(5):1055-1063.

166. Moise A, Clement B, Saltiel J. Clinical and angiographic correlates and prognostic significance of the coronary extent score. The. 1998;61(15):1255-1259.

167. Mark DB, Nelson CL, Califf RM, et al. Continuing evolution of therapy for coronary artery disease. Initial results from the era of coronary angioplasty. Circulation. 1994;89(5):2015-2025.

168. Alyan O, Kacmaz F, Ozdemir O, et al. Hepatitis C infection is associated with increased coronary artery atherosclerosis defined by modified Reardon severity score system. Circ J . 2008;72(12):1960-1965.

169. The effect of intensive treatment of diabetes on the development and progression of long-term complications in insulin-dependent diabetes mellitus. The Diabetes Control and Complications Trial Research Group. N Engl J Med. 1993;329(14):977-986. 
170. Gaster B, Hirsch IB. The effects of improved glycemic control on complications in type 2 diabetes. Arch Intern Med. 1998;158(2):134-140.

171. Klein R, Klein BE, Moss SE. Relation of glycemic control to diabetic microvascular complications in diabetes mellitus. Ann Intern Med. 1996;124(1 Pt 2):90-96.

172. Fuller JH, Shipley MJ, Rose G, et al. Mortality from coronary heart disease and stroke in relation to degree of glycaemia: the Whitehall study. Br Med J (Clin Res Ed). 1983;287(6396):867-870.

173. Balkau B, Shipley M, Jarrett RJ, et al. High blood glucose concentration is a risk factor for mortality in middle-aged nondiabetic men. 20-year follow-up in the Whitehall Study, the Paris Prospective Study, and the Helsinki Policemen Study. Diabetes Care. 1998;21(3):360-367.

174. Juutilainen A, Lehto S, Rönnemaa T, et al. Type 2 diabetes as a "coronary heart disease equivalent": an 18-year prospective population-based study in Finnish subjects. Diabetes Care . 2005;28(12):2901-2907.

175. Goldstein DE, Little RR, Lorenz RA, et al. Tests of glycemia in diabetes. Diabetes Care. 2003;26(Suppl 1):S106-S108.

176. Meigs JB, Nathan DM, Cupples LA, et al. Tracking of glycated hemoglobin in the original cohort of the Framingham Heart Study. $J$ Clin Epidemiol . 1996;49(4):411-417.

177. Rohlfing C, Wiedmeyer HM, Little R, et al. Biological variation of glycohemoglobin. Clin Chem . 2002;48(7):1116-1118.

178. American Diabetes Association. Standards of medical care in diabetes. Diabetes Care. 2004;27(Suppl 1):S15-S35.

179. Selvin E, Coresh J, Golden SH, et al. Glycemic control and coronary heart disease risk in persons with and without diabetes: the atherosclerosis risk in communities study. Arch Intern Med. 2005;165(16):1910-1916.

180. Selvin E, Coresh J, Golden SH, et al. Glycemic control, atherosclerosis, and risk factors for cardiovascular disease in individuals with diabetes. Diabetes Care. 2005;28(8):1965-1973.

181. Sasso FC, Carbonara O, Nasti R, et al. Glucose metabolism and coronary heart disease in patients with normal glucose tolerance. JAMA. 2004;291(15):1857-1863.

182. Blake GJ, Pradhan AD, Manson JE, et al. Hemoglobin A1c leve and future cardiovascular events in women. Arch Intern Med. 2004;164(7):757-761

183. Lawlor DA, Fraser A, Ebrahim S, et al. Independent associations of fasting insulin, glucose, and glycated hemoglobin with stroke and coronary heart disease in older women. PLoS Med . 2007;4(8):e263.

184. Park S, Barrett-Connor E, Wingard DL, et al. GHb is a better predictor of cardiovascular disease than fasting or post challenge plasma glucose in women without diabetes. The Rancho Bernardo Study. Diabetes Care 19(5): 450-456. Lawlor DA, Fraser A, Ebrahim S, Davey Smith G (2007) Independent associations of fasting insulin, glucose, and glycated hemoglobin with stroke and coronary heart disease in older women. PLOS Medicine. 1996;4(8):e263.

185. Huxley R, Barzi F, Woodward M. Excess risk of fatal coronary heart disease associated with diabetes in men and women: meta-analysis of 37 prospective cohort studies. BMJ. 2006; 332(7533):73-78.
186. Coutinho M, Gerstein HC, Wang Y,et al. The relationship between glucose and incident cardiovascular events. A metaregression analysis of published data from 20 studies of 95,783 individuals followed for 12.4 years. Diabetes Care. 1999;22(2):233-240.

187. Barr EL, Zimmet PZ, Welborn TA, et al. Risk of cardiovascular and all-cause mortality in individuals with diabetes mellitus, impaired fasting glucose, and impaired glucose tolerance: the Australian Diabetes, Obesity, and Lifestyle Study (AusDiab). Circulation. 2007;116(2):151-157.

188. Grant JF, Chittleborough CR, Taylor AW, et al. The North West Adelaide Health Study: detailed methods and baseline segmentation of a cohort for selected chronic diseases. Epidemiol Perspect Innov. 2006;3:4.

189. Robert Adams J, Sarah Appleton L, Catherine Hill L, et al. Independent Association of HbA1c and Incident Cardiovascular Disease in People Without Diabetes. Obesity . 2009;17(3):559-563.

190. Unwin N, Shaw J, Zimmet P, et al. Impaired glucose tolerance and impaired fasting glycaemia: the current status on definition and intervention. Diabet Med. 2002;19(9):708-723.

191. Corpus RA, O’Neill WW, Dixon SR, et al. Relation of Hemoglobin A1c to Rate of Major Adverse Cardiac Events in Nondiabetic Patients Undergoing Percutaneous Coronary Revascularization. Am J Cardiol . 2003;92(11):1282-1286.

192. Jennifer KP, Leah EC, Frank BH, et al. Hemoglobin A1c Is Associated With Increased Risk of Incident Coronary Heart Disease Among Apparently Healthy, Nondiabetic Men and Women. J Am Heart Assoc. 2013;2:e000077.

193. Kay-Tee K, Nicholas W, Sheila B, et al. Association of Hemoglobin A1c with Cardiovascular Disease and Mortality in Adults: The European Prospective Investigation into Cancer in Norfolk. Ann Intern Med. 2004;141(6):413-420.

194. Lone J, Trond J, Oddmund J, et al. Glycated Hemoglobin Level Is Strongly Related to the Prevalence of Carotid Artery Plaques With High Echogenicity in Nondiabetic Individuals. Circulation. 2004;110:466-470.

195. Jenssen T, Joakimsen O, Heuch I, et al. Glycated hemoglobin level is strongly related to the prevalence of carotid artery plaques with high echogenicity in nondiabetic individuals: the Tromsø study. Circulation. 2004;110(4):466-470.

196. M Ivan Wiggam, Maurice J O’Kane, Roy Harper, et al. Treatment of Diabetic Ketoacidosis Using Normalization of Blood 3-Hydroxybutyrate Concentration as the Endpoint of Emergency Management: A randomized controlled study Diabetes care . 1977;20(9):1347-1352.

197. The ARIC Investigators. The Atherosclerosis Risk in Community (ARIC) Study Design and Objective. European Journal of Endocrinology. 1988;129(4):687-702.

198. Kataoka Y, Yasuda S, Morii I, et al. Quantitative coronary angiographic studies of patients with angina pectorisand impaired glucose tolerance. Diabetes Care . 2005;28(9):2217-2222.

199. Liu C, Sage JC, Miller MR, et al. Mosaic analysis with double markers reveals tumor cell of origin in glioma. Cell . 2011;146(2):209-221. 